Nutrition Today

Volume 53, Issue 6, 2018, pages 268-278

\title{
Production and Polyphenolic Composition of Tea
}

Nutrition Today (accepted manuscript)

DOI: http://doi.org/10.1097/NT.0000000000000304

Authors:

Kacie K.H.Y. Ho, PhD, is an assistant professor at the University of Hawaii at Manoa, Honolulu, HI.

Thomas C. Haufe, MS, is currently a product development scientist at Mead Johnson Nutrition Inc, Department of Food Science and Technology, Virginia Tech, Blacksburg.

Mario G. Ferruzzi, PhD, is a professor of food science and nutrition at the North Carolina State University Plants for Human Health Institute, Plants for Human Health Institute, North Carolina State University, Kannapolis.

Andrew P. Neilson, PhD, is an associate professor in the Department of Food Science and Technology, Virginia Tech, Blacksburg.

Funding was provided by The Coca-Cola Company.

The authors have no conflicts of interest to disclose.

Correspondence: Andrew P. Neilson, PhD, 1981 Kraft Dr, Blacksburg, VA 24060

(andrewn@,vt.edu) 


\title{
Nutrition Today
}

Volume 53, Issue 6, 2018, pages 268-278

\begin{abstract}
Tea (Camellia sinensis) is the second most commonly consumed beverage in the world, and its consumption has been associated with several important health benefits due in part to its high concentration of polyphenolic compounds. Tea varieties, including white, green, oolong, pu-erh, and black tea, are all produced from the same plant but differ in postharvest processing. The level of oxidative processing from white to black tea (low to high) drives changes in polyphenol profiles from monomeric polyphenols (catechins) to oxidative products (theaflavins and thearubigins) that convert the subtle yellow color of green tea to the distinctive red/copper color of oolong and black tea. Poly- phenol compounds from green teas have been well studied; however, oxidative products are more difficult to characterize and may require a combination of analytical techniques for identification and quantification. This technical summary introduces the major polyphenols in tea and discusses the main steps of tea processing and instrumentation used for polyphenol analysis.
\end{abstract}




\section{Nutrition Today}

Volume 53, Issue 6, 2018, pages 268-278

\section{Introduction}

Camellia sinensis (L.) Kuntze is a perennial leafy crop, which is steeped in hot water to produce non-herbal types of brewed tea. As the second most commonly consumed beverage in the world (second only to water) ${ }^{1}$, tea popularity is a result of historical/cultural traditions, stimulant properties due to caffeine, and potential preventative actions against chronic disease $\mathrm{e}^{1-3}$ such as cardiovascular disease $e^{4}$. Tea is also a massively traded global commodity: about 3.2 million metric tons of tea were produced in 2010 , where $\sim 60-80 \%$ of this was black tea, $\sim 20$ $30 \%$ was green tea, and less common teas, e.g., oolong, accounted for the remainder ${ }^{1}$. Considering the thousands of years of traditional use for its purported medicinal and nutritional properties in Eastern Asian cultures and, more recent preclinical and clinical research supporting a role for tea in health ${ }^{1}$,it is increasingly important to distinguish the chemical characteristics of typical tea beverages consumed around the world. This narrative review covers the chemical composition of brewed tea and derived tea beverages with a focus on defining ranges of known bioactive components (i.e. phenolics) associated with the health benefits of tea. Although there are several bioactive components in tea, this review will focus on the major classes (e.g., catechins, theaflavins, and thearubigins). Tables (1A-C) included in this technical review are intended to give the reader a broad idea of typical tea polyphenol ranges rather than a comprehensive list. For further information, readers can refer to other publications ${ }^{5,6}$, which have also summarized flavonoid content of different types of tea. Table 1A, 1B, and 1C list levels of catechins and theaflavins in brewed tea, dried tea, and normalized in a US customary cup, respectively. Overall, the tea polyphenol concentration in dried tea vs. brewed tea will vary depending on the type of tea and the extraction conditions. Additionally, in order to compare results across studies, comparing a normalized unit (e.g., US customary cup) is helpful for 


\section{Nutrition Today}

Volume 53, Issue 6, 2018, pages 268-278

comparisons and for application to what an average person might drink. Table 2 is included to highlight the techniques (including extraction method and instrumentation) that have been used to identify polyphenols from tea. Although limited in literature compared to conventional tea, Tables 3A and 3B highlight some of the polyphenol levels reported in instant and ready-to-drink (bottled or canned) tea, respectively. Levels in tea beverage products can vary widely across studies as the various processing conditions affect the resulting polyphenolic profile. Since this review is focusing on major polyphenols (e.g., catechins, theaflavins, thearubgins), theanine and caffeine, which are also major bioactive compounds in tea, have been excluded from the presented tables. Interested readers are encouraged to consult additional literature or to contact the authors to view extended versions of Tables 1 and 3, which include information on theanine and caffeine.

Although this technical review focuses on tea production and polyphenol composition, the topics covered provide the basic foundation needed to understand the potential health benefits of tea. Findings from human and clinical studies can only be collectively and accurately interpreted if tea products used across studies are comparable. Thus, understanding the basics of tea polyphenols (including the typical quantity in cup) is a critical prerequisite for research findings to have significant health impacts.

\section{The chemistry of tea}

The beneficial health effects of tea have largely been attributed to the polyphenol compounds, including: flavanols, flavonols, phenolic acids, proanthocyanidins, theaflavins, thearubigins ${ }^{1,7}$ (Figure 1). Concentration and type of polyphenolic compounds are highly variable between (and within) different tea types (white, green, black, oolong, etc.) due to differences in maturity at harvest, seasonal variation, and processing ${ }^{8,9}$. There are over 300 


\section{Nutrition Today \\ Volume 53, Issue 6, 2018, pages 268-278}

varieties of tea, but the most commonly consumed are green, oolong, and black tea ${ }^{10}$, which are all produced from the Camellia sinensis plant using different processing methods. This technical summary will focus on both non-oxidized or "unfermented" (white and green) and oxidized or "fermented" (oolong, black and pu-erh) teas.

Figure 1. Basic structures of phenolic compounds found in green, oolong and black tea. Figure adapted from previous source ${ }^{1,7}$.

\begin{tabular}{|c|c|c|c|}
\hline & $C^{R_{2}}$ & 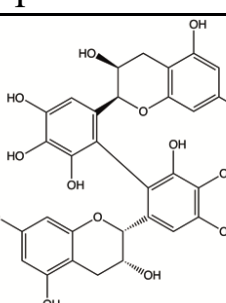 & ${ }^{\text {Hо }}$ \\
\hline $\begin{array}{c}\text { Catechin backbone } \\
\text { Epicatechin }= \\
R_{1}=\mathrm{R}_{2}=\mathrm{H} \\
\text { Epigallocatechin }=\mathrm{R}_{1} \\
=\mathrm{H}, \mathrm{R}_{2}=\mathrm{OH} \\
\text { Epicatechin gallate }= \\
\mathrm{R}_{1}=\text { gallate, } \mathrm{R}_{2}=\mathrm{H} \\
\text { Eigallocatechin } \\
\text { gallate }=\mathrm{R}_{1}=\text { gallate, } \\
\mathrm{R}_{2}=\mathrm{OH}\end{array}$ & 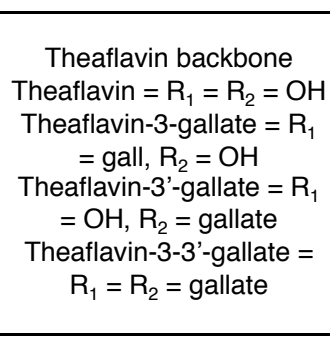 & Theasinensin C & Thearubigins (generalized structure) \\
\hline
\end{tabular}

\section{Tea production and harvest}

The Camellia sinensis tea plant grows in moist, warm climates $\left(10-30^{\circ} \mathrm{C}\right)$ with acidic soils in elevated areas up to $2000 \mathrm{~m}^{11}$. Asia dominates the world tea production market with mainland China and India as the top producers in $2013^{11}$. On plantations (Figure 2A), tea can be harvested using manual, partially mechanical (Figure 2B), or automated methods ${ }^{9}$. Hand picking is a requirement for white tea and some green teas as these are produced from only the bud or the bud and the upper leaves (Figure 2C). Throughout the harvest season, the tea plant is regularly pruned and re-picked every 1-2 weeks ${ }^{9}$. The timing of harvest is critical for some teas, as white teas are harvested in the spring and high-grade green teas are harvested from late April to early May, with the quality declining later in the year'. 


\section{Nutrition Today}

\section{Volume 53, Issue 6, 2018, pages 268-278}

Tea leaf maturity may affect the polyphenolic profile, however, other variables, such as climate, tea plant variety, cultivation practices, and season all act as additional factors. In one study, the bud and young leaves contained higher levels of (-)-epicatechin gallate (ECG) and (-)epigallocatechin gallate (EGCG) while the mature leaves had higher levels of (-)epigallocatechin (EGC) and (-)-epicatechin (EC) ${ }^{8}$. However, others have reported that mature leaves contain higher levels of EGCG and EC but less caffeine than the young leaves ${ }^{9}$. The difference in findings is likely due to the picking method (e.g., picking leaves 1-4 vs. 1-10) and the season (spring vs. summer), where higher numbered leaves indicate they are more mature (Figure 2C).

Figure 2. Tea plantation in Munnar, India (A),tea leaf cutting and harvest (B), and tea plant with bud and leaves. Photographs courtesy of Jordan Oshiro.






\section{Tea processing}

The specifics of commercial tea processing vary depending on the manufacturer, however there are notable differences in steps used to produce white, green, pu-erh, oolong, and black teas $^{12,13}$ (Figure 3). The extent of post-harvest fermentation dictates the style of tea: white and green teas are unfermented, oolong tea is partially fermented, and black tea is fully fermented. True microbiological fermentation occurs in some teas, such as pu-erh tea. However, for oolong and black tea, the term "fermentation" is actually a misnomer as the process is enzymatic and induces degradation/conjugation of tea polyphenols with naturally occurring enzymes in tea leaves (polyphenol oxidase and peroxidase).

Figure 3. Comparative overview of processing steps for white, green, pu-erh, ooong, and black tea. Figure developed from previous sources ${ }^{1,12,13,16,17}$.

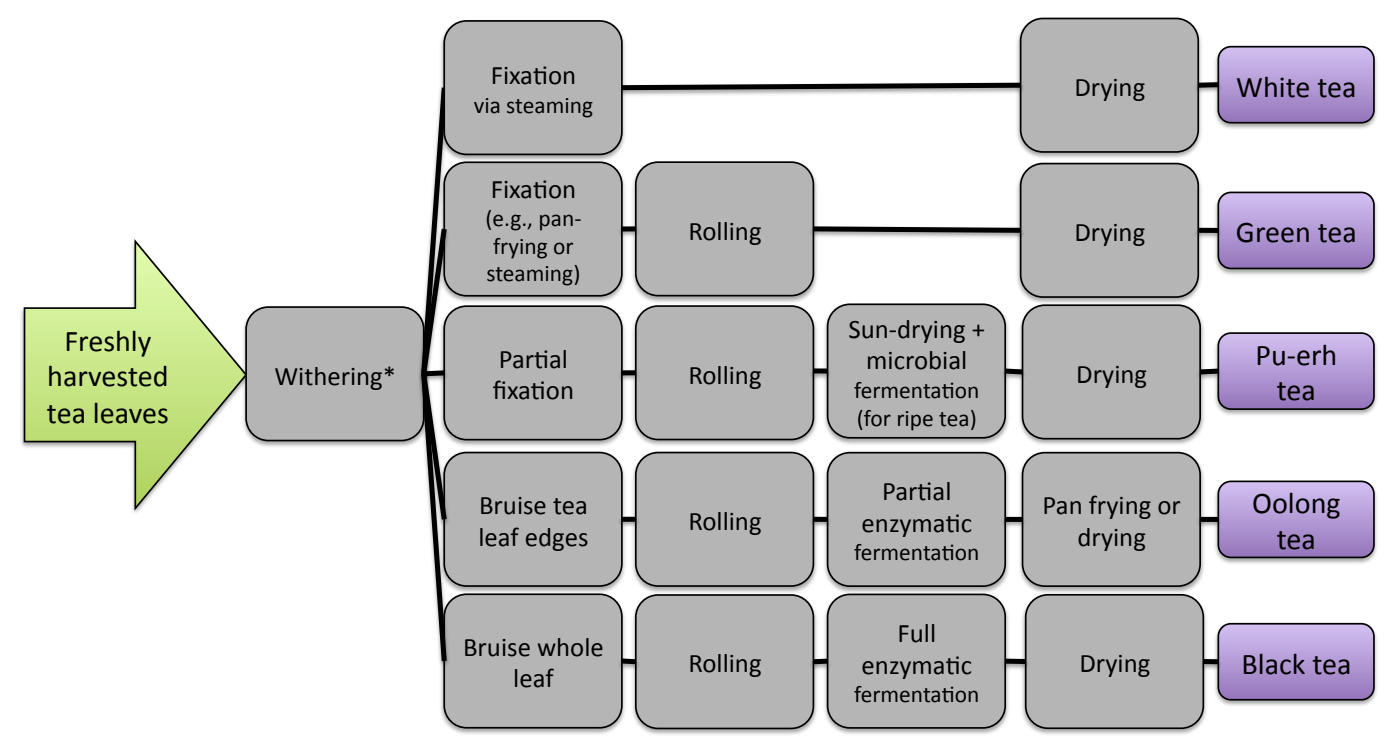

*Withering for white tea and Japanese style green tea is limited or excluded to prevent excessive oxidation. 


\section{Nutrition Today}

Volume 53, Issue 6, 2018, pages 268-278

\section{White tea}

The name of white tea is derived from the white "hair" that covers the tips of the young Camellia sinensis tea buds at the time of harvest. Chinese white teas are generally graded by their maturity at the time of harvest: high quality/bud only (BaiHaoYinZhen or silver needle), a bud with one or two leaves (BaiMuDan or white peony), or more than two leaves (ShouMei) ${ }^{14}$. In general, white tea is subjected to very light post-harvest processing methods, usually sun-drying or steaming and drying, which preserves the fresh quality characteristics. In China, white tea is characterized as specific tea sub-species (Camellia sinensis var. fudin bai hao and var. khenghebai hao) found seasonally in the Fujian province, which is minimally processed according to traditional guidelines ${ }^{12}$.

As a relatively rare and expensive tea, due in part to its stringent picking requirements, white tea has been less researched compared to other teas ${ }^{15}$. Due to this and to the variation in polyphenolic profile amongst white tea grades, it has been difficult to conclude a hierarchical order of polyphenol content in white tea compared to other teas. However, when comparing various white tea grades, catechin content appeared to decrease with increasing maturity of tea leaves from different seasons, with tea harvested in early spring having the highest average catechin content, of which, (-)-epigallocatechin gallate (EGCG) was predominant ${ }^{14}$.

\section{Green tea}

Similar to white tea, green tea is also "unfermented. During green tea processing, the endogenous polyphenol oxidase and peroxidase enzymes in the leaves are deactivated by steaming (Japanese-style) or pan-frying (Chinese-style) ${ }^{12}$. Different varieties of green tea are produced by using tea plants of different age, varied ratios of tea leaves to tea buds, different amounts of shading during cultivation, and sourcing tea leaves from distinct geographical 


\section{Nutrition Today}

Volume 53, Issue 6, 2018, pages 268-278

regions. A notable example of this is Japanese-style green tea, which is generally produced from a shade-grown hybrid².

Green tea contains a high amount of catechin monomers: in a normal tea infusion (i.e. $\sim 2.5$ grams of tea brewed into $\sim 250 \mathrm{~mL}$ of near-boiling water), about $30-40 \%$ of the solids in the infusion are dissolved catechins which is equal to $\sim 100 \mathrm{mg}$ catechins per $100 \mathrm{~mL}^{10}$. The major green tea polyphenols are flavanols: (-)-epicatechin (EC), (-)-epicatechin gallate (ECG), (-)epigallocatechin (EGC), and (-)-epigallocatechin gallate (EGCG), where EGCG is the predominant catechin in green tea ${ }^{10}$. These catechins are consistently found in green tea because endogenous polyphenol oxidase and peroxidase enzymes are inactivated by steam or dry heat in order to prevent oxidation and polymerization of the catechins. Other prevalent polyphenolic compounds in green tea include: $(+)$-gallocatechin and $(+)$-catechin, among others. The exact composition of different green teas can vary widely depending on many factors: geographical location, growing conditions (sunlight levels, soil composition, moisture, etc.), varietal differences between strains of Camellia sinensis (hybrids of var. sinensis and var. assamica), and post-harvest processing methods (sun-dried, steamed, oven-fired, etc.).

\section{Pu-erh tea}

$\mathrm{Pu}$-erh tea is a less common sun-dried tea variety and is sometimes included in a class of teas known as Chinese dark teas ${ }^{16}$. There are different variations of pu-erh tea, which differ in extent of fermentation (raw vs. ripe) and may be loose or compressed into a cake of different shapes ${ }^{13}$. Similar to green tea, pu-erh tea undergoes a fixation step for enzyme inactivation. However, this heating step (typically conducted in a heating drum) is mild and may not inactivate all enzymes ${ }^{17}$. Ripened pu-erh tea is unique as there is a microbial fermentation step, which produces characteristic aroma and bioactive compounds ${ }^{16}$. This microbial fermentation 


\section{Nutrition Today \\ Volume 53, Issue 6, 2018, pages 268-278}

step is usually referred to as "heap fermentation" during which the leaves are kept in humid conditions and may be inoculated with the desired microbe (often Aspergillus sp.) and allowed to ferment under ambient conditions ${ }^{16}$. The polyphenolic composition of pu-erh tea is not as well defined as other tea types as it contains highly polymerized catechins ${ }^{16}$, which are difficult to identify and quantify ${ }^{18}$.

\section{Oolong tea}

Oolong tea is a semi-enzymatically fermented tea variety. For production, tea leaves are harvested, partially bruised (e.g., the leaf edges) to decompartmentalize the enzymes and catechins (facilitating subsequent fermentation), and then partially fermented; the degree of fermentation of oolong teas ranges from $10-80 \%$ (i.e. $10-80 \%$ of the native catechins are oxidized and/or polymerized) ${ }^{19}$.

The composition of partially fermented oolong tea is intermediate between green and black teas due to its high catechin content and presence of theaflavins and thearubigins, the products of catechin fermentation ${ }^{8}$. Thus, it is logical to assume that less fermented oolong teas possess higher amounts of catechins and lower levels of theaflavins/thearubigins while the inverse is true for oolong tea that has been more fermented/oxidized.

\section{Black tea}

The characteristic flavors associated with black tea are the result of enzymatic transformation by endogenous, naturally occurring polyphenol oxidase and peroxidase enzymes during processing. The rolling step (Figure 3) can be done using orthodox methods or with crush-tear-curl (CTC) machines, the latter of which being more destructive and better at facilitating decompartmentalization and thus enzymatic fermentation ${ }^{1}$. The time and temperature 


\section{Nutrition Today}

Volume 53, Issue 6, 2018, pages 268-278

parameters of the fermentation process can widely vary depending on the tea producer but generally the leaves are fermented at about $40^{\circ} \mathrm{C}$ for about $1-2$ hours ${ }^{2}$.

Theaflavins are oxidized dimers of the catechin monomers while thearubigins are oxidized polymers of the catechins ${ }^{10}$. Common theaflavins include theaflavin, theaflavin-3gallate, theaflavin-3'-gallate, and theaflavin-3,3'-diagallate ${ }^{10}$. Theaflavins and thearubigins impart important quality characteristics to black tea including mouthfeel and color; these compounds are responsible for the dark reddish-brown color of black tea ${ }^{10}$. Thearubigins are also a significant component of black teas: $60-70 \%$ of the dissolved solids in a black tea infusion are thearubigins ${ }^{18}$. The astonishingly high number of unique thearubigins is due to extensive polymerization and oxidation of the theaflavins; these compounds have a number of sites available for oxidation, and different sized polymers are formed during fermentation ${ }^{18}$.

\section{Tea products}

Tea sold as loose leaves or in tea bags continues to be popular, however consumers now have options that favor convenience over tradition. Instant teas are dried tea powders that can be added back to cold water without brewing. The first documentation of instant tea is believed to be from a patent from the United Kingdom in 1885, although significant development of instant teas did not begin until the 1940s, after the invention of spray-drying, which allowed for rapid drying and limited degradation of tea flavors ${ }^{20}$. Depending on the type of tea and the specific product outcomes, instant tea is generally produced by spray or freeze-drying a tea extract to produce a powdered solid and may involve additional steps to retain aromas or maintain quality, such as aroma stripping and cream processing ${ }^{20}$. Powdered green tea has shown to been stable against catechin degradation during storage, given that the storage conditions are favorable $(\leq 69 \% \text { relative humidity })^{21}$. 


\section{Nutrition Today \\ Volume 53, Issue 6, 2018, pages 268-278}

ITO EN, Ltd., a Japanese company, successfully produced the first canned oolong and green teas in the 1980's and the first bottled green tea in $1990^{22}$. Since then, the global consumption of ready-to-drink (RTD) teas has steadily grown, at a rate faster than soda, and is

expected to exceed 45 billion liters by $2021^{23}$. RTD tea products are often produced from instant tea powder and are decreamed/clarified (typically by centrifugation or filtration to remove components that precipitate in cold tea) and then sterilized via retort and canned or via ultra-high temperature (UHT) processing and packaged in polyethylene terephthalate (PET) bottles ${ }^{24}$. Although it depends on the specific manufacturing conditions, catechins can be epimerized during heat treatment of canned or bottled products ${ }^{25}$. These products can also be acidified, which can help to limit degradation of tea catechins during the heating stage ${ }^{26}$.

\section{Analytical methods for tea polyphenols}

Since tea contains a mix of various polyphenolic compounds, samples must undergo a process to separate the various components before they can be individually identified and quantified. General approaches for identifying tea polyphenols can be categorized as targeted, when the compounds to be analyzed are preselected based off of prior knowledge, or untargeted, which is hypothesis-free and aims to screen for all potential compounds. Targeted approaches are appropriate when the identity of polyphenols are well known and often allows for good resolution as compounds are selectively screened. Untargeted approaches, also known as fingerprinting, have been adapted to food research from the field of metabolomics ${ }^{27}$ and are advantageous for identifying a unique polyphenol fingerprint (profile) of a poorly characterized sample (e.g., processed or oxidized tea or metabolites found in humans after tea consumption). A variety of techniques and strategies can be used for untargeted approaches, all of which aim to elucidate compounds that might otherwise be missed in targeted analyses. 


\section{Nutrition Today}

Volume 53, Issue 6, 2018, pages 268-278

Prior to analysis, tea specimens often need to be prepared in such a way so that the target analytes can be efficiently identified and/or separated from other components, depending on the method of analysis. Chromatographic methods are commonly employed as a strategy for separating bioactive compounds in tea infusions or biological samples. In particular, liquid chromatography such as high-performance liquid chromatography (HPLC) or ultra-performance liquid chromatography (UPLC), is a useful tool that has been reliably used for tea polyphenol separation.

Simply put, a tea sample (in liquid form) can be moved through an HPLC or UPLC instrument in a stream of specific liquid solvent(s). The liquid solvent stream and sample are passed through a column, which will retain or release components in the sample at different times, depending on the compound, instrument conditions, the column, and the liquid solvent(s) passing through the system. Essentially, different tea polyphenols have different physical and chemical properties, which will allow them to leave the column at different times allowing them to be separated. After chromatographic separation, these analytes are identified and/or quantified with detectors, such as UV/vis detectors (diode array detectors), mass spectrometers, ultraviolet, and electrochemical detectors. HPLC coupled with mass spectrometry has become a prevalent analytical tool for tea bioactive compounds due to its versatility to analyze a wide range of compounds in tea samples as well as in biological tissues samples ${ }^{28}$. Table 2 provides an overview of recent analytical methods used to quantify tea polyphenols from different tea sources. Innovations in column efficiency (e.g., smaller particle packing size) and improved systems operating at high backpressures have allowed for high sensitivity and resolution ${ }^{29}$ of tea polyphenols. HPLC and UPLC analyses of tea polyphenols and phenolic acids can serve a variety of purposes for the tea producer: verification of polyphenol label claims, quality 
Nutrition Today

Volume 53, Issue 6, 2018, pages 268-278

assurance of finished product, validation of geographical origin of the tea leaves ${ }^{30}$, guidance during the product development process, and quality control of raw input ingredients.

\section{Challenges with tea polyphenol analysis.}

Currently, methodologies for green tea are further developed compared to those for oolong, pu-erh, and black teas due to the simplicity of resolving and identifying the monomeric green tea catechins via chromatographic methods. Table 2 summarizes common chromatographic methods used to analyze catechins in tea infusions. Oxidized, polymerized black tea polyphenols have traditionally been difficult to analyze due to their highly complex nature and lack of analytical standards for these compounds. Recent research has shown the presence of thousands of different compounds in a single sample of black tea, with molecular weights between 1,000 and 2,100 daltons ${ }^{18}$. These "high molecular weight" compounds found in black tea, the thearubigins, have long been poorly characterized due to simultaneous elution (compounds aren't well separated) and large molecular weight, which prevents analysis by many mass spectrometers (essentially all common instruments except time-of-flight). However, research from the Kuhnert lab at the Jacobs University Bremen has partially elucidated individual thearubigins through a combination of analytical methods (including different types of mass spectrometry $)^{7,18}$. These papers delve into the molecular mechanisms by which enzymes of the tea fermentation process are able to create a vast quantity of thearubigins as well as the method used to obtain these data. The authors demonstrated the presence of over 5,000 unique thearubigins within a single black tea sample; these compounds were theorized to be formed through a "cascade" of oxidation, condensation, and other reactions during the fermentation process. These data further confirm the difficulty of effective characterization of thearubigins present in black, which prevents strict standardization of black tea products and potentially 
Nutrition Today

Volume 53, Issue 6, 2018, pages 268-278

obscures these compounds' activities in human clinical trial research.

\section{Non-specific methods for polyphenol analysis}

It is important to note that early methodologies to measure total polyphenols (i.e. FolinCiocalteu) and flavan-3-ols (DMAC, Vanillin, Porter, etc.) are still valuable as complementary assays. However, these methods are highly simplistic in that they do not provide selectivity/specificity to differentiate polyphenol classes. These assays may be used to complement HPLC, NMR, etc., but should not be relied upon as primary analytical methods. Most quality peer-reviewed journals have adopted policies that recognize these limitations, and require HPLC or other specific methods for bioactive compounds in tea. Furthermore, it is important to recognize that Folin is primarily a reducing activity assay, even though it is mistakenly reported as a "total phenols" or "total polyphenols" assay. This is only the case when the vast majority of the reducing activity comes from polyphenols as it could overestimate the polyphenol content.

\section{Comparison of polyphenol levels in tea products}

The amount of polyphenols actually consumed in tea beverages depends on several factors including 1) their concentration in the tea leaves, 2) the mass of tea leaves used to prepare the infusion, 3) the volume of water used to prepare the infusion, 4) the water temperature, brew time, and agitation (i.e. extraction variables) used to prepare the infusion, 5) the $\mathrm{pH}$ of the water used to prepare the infusion, thermal processing (for commercial tea infusions) and duration between preparation and consumption (all of these affect tea stability), and finally 6) the volume

of the infusion actually consumed. These parameters are highly variable in both commercial and home-prepared infusions, and lead to considerable ambiguity regarding tea composition. For example, significant differences exist in the $\mathrm{mL}$ volume of a "cup", such as metric cup (250 


\section{Nutrition Today}

Volume 53, Issue 6, 2018, pages 268-278

$\mathrm{mL})$, US customary cup (236.6 mL), US “legal” cup (240 mL), Imperial cup (284 mL), Canadian cup (227.3 mL), Japanese cup (200 mL) and others. Tables 1A-B list tea concentrations as a function of both infusion preparation (mass used) and volume $(\mathrm{mg} / 100 \mathrm{~mL}$ ) and Table 1C lists the typical ranges of major tea bioactives in a US customary cup.

While the level of polyphenols in brewed tea is often dependent on the flavor/strength preference of the drinker, in theory, instant and RTD drinks can be made more concentrated by manufacturers. In a sense, production of instant tea allows manufacturers to produce a tea powder that is more concentrated in polyphenols and is in a form that is more extractable (meaning more polyphenols are transferred into hot or cold water) compared to bagged or looseleaf tea (Table 3A) although the final polyphenol content of the beverage is dependent on dilution to a palatable level. In reality, most commercially produced beverages (for the general population) are usually formulated based on taste and quality as opposed to nutrition or bioactive compound profile. Furthermore, for RTD products, thermal processing used to ensure product safety can induce degradation of catechins and other bioactives. Studies have generally indicated lower catechin levels in RTD tea products relative to freshly brewed tea, likely due to autooxidation of catechins (Table 3B). However, it is unknown if these degradation reactions actually reduce subsequent bioactivity, as comparatively little is known regarding the activity of tea-catechin auto-oxidation dimers and epimers.

\section{Future outlook of tea and tea products}

Based on current knowledge, maximizing initial infusion levels and subsequent stabilization of tea catechins by minimizing heat treatment and maintaining moderate $\mathrm{pH}(3-5)$ is thought to be best practice for delivery of high levels of bioactive catechins. However, this is subject to change as the understanding of biological relevance of oxidation products and epimers 


\section{Nutrition Today \\ Volume 53, Issue 6, 2018, pages 268-278}

and cleavage products, such as phenolic acids, evolves. Additionally, changes and optimization in processing can help increase the polyphenol content of tea products. In general, considering the global popularity of tea, the wide array of tea varieties and product types, and potential health benefits, there are opportunities for tea to both persist in our diets as a traditionally brewed drink and to further evolve into new and convenient beverage products that provide significant quantities of bioactive catechins and other compounds. 


\section{Nutrition Today}

Volume 53, Issue 6, 2018, pages 268-278

Table 1A. Levels of main bioactive classes found in representative brewed tea samples

\begin{tabular}{|c|c|c|c|c|c|}
\hline Type of tea & $\begin{array}{l}\text { Amount of tea } \\
\text { added to water for } \\
\text { brewing }\end{array}$ & $\begin{array}{l}\text { Catechins } \\
(\mathrm{mg} / 100 \mathrm{~mL})\end{array}$ & $\begin{array}{l}\text { Theaflavins } \\
\text { (mg/100 mL) }\end{array}$ & Reference & \\
\hline Green tea & $2.2 \mathrm{~g}$ in $250 \mathrm{~mL}$ & 71 & & 35 & \\
\hline Oolong tea & $2.2 \mathrm{~g}$ in $250 \mathrm{~mL}$ & 44 & & 35 & \\
\hline Black tea ( & $2.2 \mathrm{~g}$ in $250 \mathrm{~mL}$ & 20 & 1.8 & 35 & \\
\hline Black tea & $\begin{array}{l}1 \text { tea bag in } 236 \\
\mathrm{~mL}\end{array}$ & 52 & 3.7 & 36 & \\
\hline Green tea & $\begin{array}{l}1 \text { tea bag in } 236 \\
\mathrm{~mL}\end{array}$ & 96 & & 36 & \\
\hline Green tea & $\begin{array}{l}1 \text { tea bag in } 240 \\
\mathrm{~mL}\end{array}$ & 71 & $\mathrm{ND}^{2}$ & 37 & \\
\hline Black tea & $\begin{array}{l}1 \text { tea bag in } 240 \\
\mathrm{~mL}\end{array}$ & 6 & 2.5 & 37 & \\
\hline $\begin{array}{l}\text { Green tea } \\
(1 \mathrm{~g} \text { in } 18 \\
\mathrm{mL})^{3}\end{array}$ & $1 \mathrm{~g}$ in $18 \mathrm{~mL}^{3}$ & $457^{3}$ & $\mathrm{ND}^{2}$ & 38 & \\
\hline Black tea & $1 \mathrm{~g}$ in $18 \mathrm{~mL}^{3}$ & $10^{3}$ & $22^{3}$ & 38 & \\
\hline $\begin{array}{l}8 \text { white tea } \\
\text { samples }\end{array}$ & $0.5 \mathrm{~g}$ in $20 \mathrm{~mL}$ & $\begin{array}{l}24 \text { (range 8- } \\
54)^{1}\end{array}$ & 0 & 39 & \\
\hline
\end{tabular}

${ }^{1}$ This value represents the mean of the 8 white tea samples with the range of levels of total catechins and caffeine ${ }^{2} \mathrm{ND}=$ not detected

${ }^{3}$ Note: in this analysis, the tea was brewed at a high concentration $(1 \mathrm{~g}$ tea leaves per $18 \mathrm{~mL}$ water) which is not representative of normal tea strength, hence the high levels of some analytes 


\section{Nutrition Today}

Volume 53, Issue 6, 2018, pages 268-278

Table 1B. Levels of main bioactive classes found in processed, dried tea product

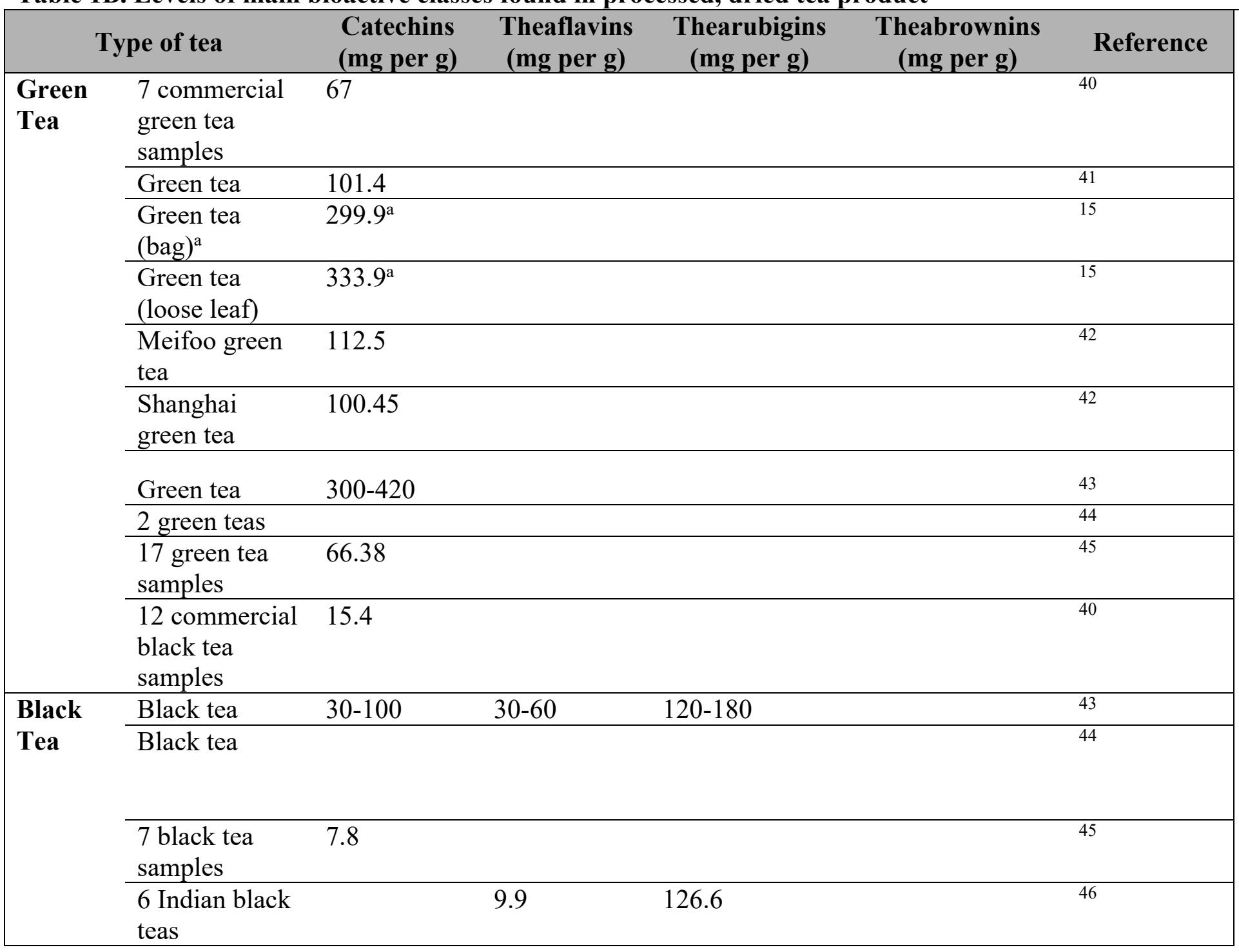




\section{Nutrition Today}

Volume 53, Issue 6, 2018, pages 268-278

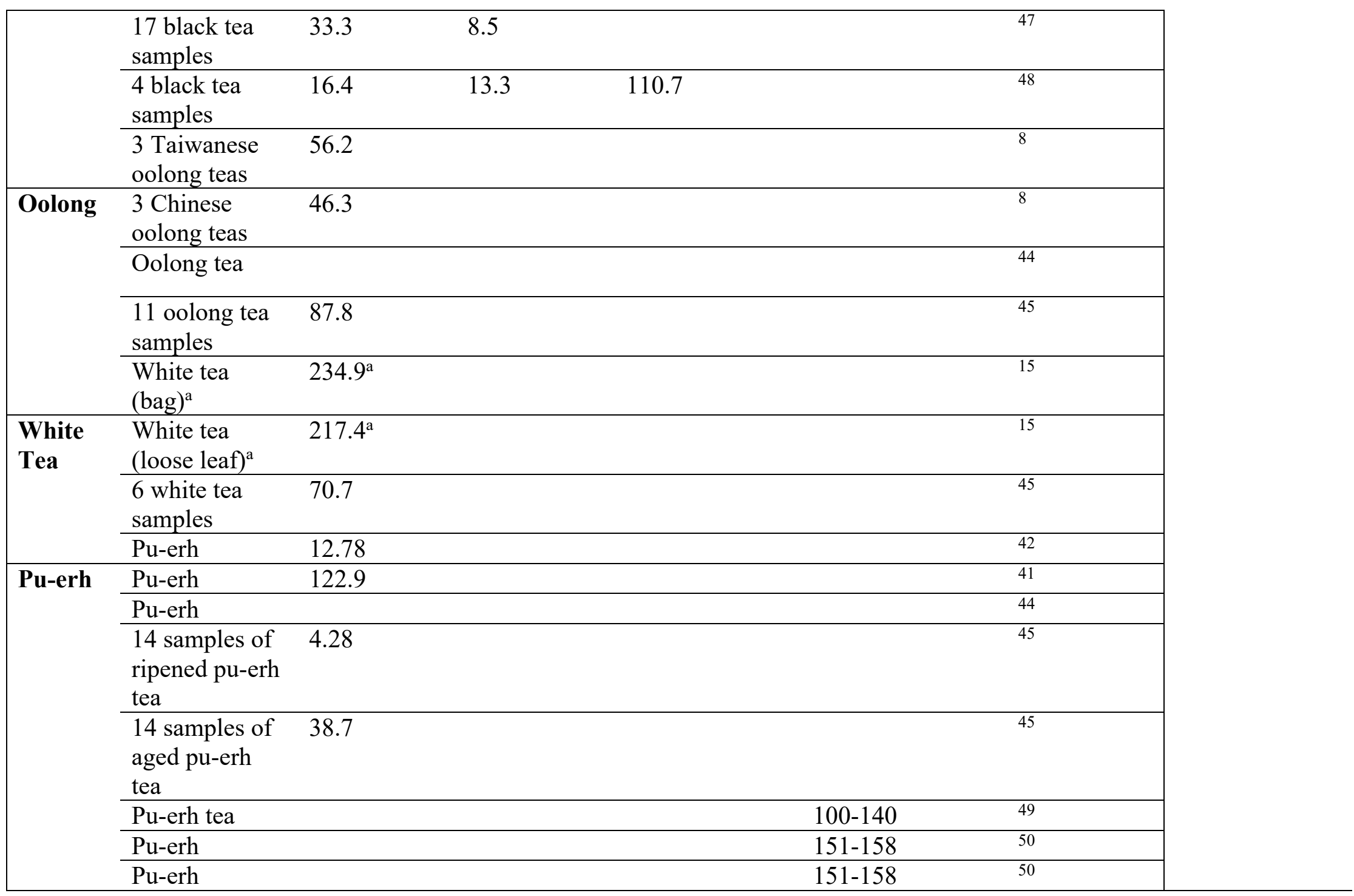


Nutrition Today

Volume 53, Issue 6, 2018, pages 268-278

Table 1C. Typical ranges for tea bioactives and common ranges in a US Customary Cup $(237 \mathrm{~mL})$ of tea*

\begin{tabular}{|c|c|c|c|c|c|}
\hline $\begin{array}{c}\text { Tea } \\
\text { Type }\end{array}$ & $\begin{array}{c}\text { Characteristic } \\
\text { Component }\end{array}$ & $\begin{array}{c}\text { Reported } \\
\text { Range per } \\
237 \mathrm{~mL} \text { Cup }\end{array}$ & $\begin{array}{c}\text { Reasonable } \\
\text { Target per } \\
\text { 237mL Cup }\end{array}$ & $\begin{array}{c}\text { Common } \\
\text { Methodology }\end{array}$ & Reference \\
\hline \multirow[t]{6}{*}{ Green } & $\begin{array}{l}\text { Flavan-3-ols } \\
\text { (monomers) }\end{array}$ & $20-1197 \mathrm{mg}$ & $>250 \mathrm{mg}$ & LC-UV & 25 \\
\hline & $\begin{array}{c}\text { Flavan-3-ols } \\
\text { (oxidized) }\end{array}$ & $1-11 \mathrm{mg}$ & $\mathrm{N} / \mathrm{A}$ & LC-UV & 25 \\
\hline & $\begin{array}{c}\text { Total } \\
\text { Polyphenols }\end{array}$ & & $>300 \mathrm{mg}$ & $\begin{array}{c}\text { Folin- } \\
\text { Ciocalteu } \\
\text { method }\end{array}$ & \\
\hline & Caffeine & $35-74 \mathrm{mg}$ & $>50 \mathrm{mg}$ & LC-UV & 26,27 \\
\hline & Theobromine & $2-3 \mathrm{mg}$ & $>2 \mathrm{mg}$ & LC-UV & 26 \\
\hline & L-theanine & $5-12 \mathrm{mg}$ & $>5 \mathrm{mg}$ & $\begin{array}{c}\text { LC-UV or } \\
\text { LC- } \\
\text { Fluorescence }\end{array}$ & 28 \\
\hline \multirow[t]{6}{*}{ Black } & $\begin{array}{l}\text { Flavan-3-ols } \\
\text { (monomers) }\end{array}$ & $7-253 \mathrm{mg}$ & $>150 \mathrm{mg}$ & LC-UV & 25 \\
\hline & $\begin{array}{c}\text { Flavan-3-ols } \\
\text { (oxidized) }\end{array}$ & $115-355 \mathrm{mg}$ & $>200 \mathrm{mg}$ & LC-UV & 25 \\
\hline & $\begin{array}{c}\text { Total } \\
\text { Polyphenols }\end{array}$ & & $>350 \mathrm{mg}$ & $\begin{array}{l}\text { Folin- } \\
\text { Ciocalteu } \\
\text { method }\end{array}$ & \\
\hline & Caffeine & $33-81 \mathrm{mg}$ & $>50 \mathrm{mg}$ & LC-UV & 26,27 \\
\hline & Theobromine & $3-5 \mathrm{mg}$ & $>3$ & LC-UV & 26 \\
\hline & L-theanine & $11-42 \mathrm{mg}$ & $>15 \mathrm{mg}$ & $\begin{array}{c}\text { LC-UV or } \\
\text { LC- } \\
\text { Fluorescence }\end{array}$ & 28 \\
\hline
\end{tabular}

* Note: Cup of tea is defined as $237 \mathrm{~mL}$ based on an 6oz standard US serving. This level provides a standard for brewed tea that can be emulated in terms of total content in RTD products.

\#Note: These levels are proposed based on characteristic components present in tea brews and not on levels directly linked to specific health benefits. However, it would be expected that production of a beverage with at least these levels of characteristic components from tea would be consistent with brewed tea that is linked to health benefits in epidemiological studies. 
Nutrition Today

Volume 53, Issue 6, 2018, pages 268-278

Table 2. Analytical methods used to identify and quantify bioactive compounds in tea products

\begin{tabular}{|c|c|c|c|c|c|c|c|}
\hline $\begin{array}{l}\text { Type of } \\
\text { Tea }\end{array}$ & $\begin{array}{l}\text { Sample } \\
\text { Preparatio } \\
\text { n }\end{array}$ & $\begin{array}{l}\text { Method } \\
\text { Type }\end{array}$ & Mobile Phase & Analytes ${ }^{a}$ & $\begin{array}{l}\text { Advantag } \\
\text { es }\end{array}$ & $\begin{array}{l}\text { Disadvant } \\
\text { ages }\end{array}$ & $\begin{array}{l}\text { Refere } \\
\text { nce }\end{array}$ \\
\hline $\begin{array}{l}\text { Green } \\
\text { tea and } \\
\text { black tea } \\
\text { from } \\
\text { different } \\
\text { geograp } \\
\text { hical } \\
\text { regions }\end{array}$ & $\begin{array}{l}\text { Water } \\
\text { extraction }\end{array}$ & $\begin{array}{l}\text { UV/Vis } \\
\text { spectrosc } \\
\text { opy }\end{array}$ & N/A & $\begin{array}{l}\text { All } \\
\text { polyphenols } \\
\text { (no } \\
\text { separation } \\
\text { occurs in } \\
\text { this } \\
\text { method) }\end{array}$ & $\begin{array}{l}\text { Rapid, } \\
\text { easy } \\
\text { method of } \\
\text { determinat } \\
\text { ion of } \\
\text { geographi } \\
\text { cal origin, } \\
\text { could be } \\
\text { useful in } \\
\text { QA/QC } \\
\text { applicatio } \\
\text { ns }\end{array}$ & $\begin{array}{l}\text { No } \\
\text { quantificat } \\
\text { ion of } \\
\text { individual } \\
\text { compound } \\
\text { s, } \\
\text { extensive } \\
\text { sampling } \\
\text { needed for } \\
\text { method } \\
\text { validation }\end{array}$ & 30 \\
\hline $\begin{array}{l}\text { Green, } \\
\text { white } \\
\text { and } \\
\text { black } \\
\text { teas }\end{array}$ & $\begin{array}{l}\text { Water } \\
\text { extraction }\end{array}$ & $\begin{array}{l}\text { UPLC- } \\
\mathrm{MS} / \mathrm{MS}\end{array}$ & $\begin{array}{l}0.1 \% \text { formic acid } \\
\text { (aq.), } 0.1 \% \text { formic } \\
\text { acid in } \mathrm{MeOH}\end{array}$ & $\begin{array}{l}8 \text { catechins } \\
(\mathrm{C}, \mathrm{CG}, \mathrm{EC} \text {, } \\
\mathrm{ECG}, \mathrm{EGC}, \\
\text { EGCG, GC, } \\
\text { GCG })\end{array}$ & $\begin{array}{l}\text { Fast } \\
\text { method (4 } \\
\text { min. } \\
\text { runtime) } \\
\text { allows for } \\
\text { accurate } \\
\text { quantificat } \\
\text { ion of } 8 \\
\text { catechins } \\
\text { in black, } \\
\text { green and } \\
\text { white teas }\end{array}$ & & 51 \\
\hline $\begin{array}{l}\text { Black } \\
\text { tea }\end{array}$ & $\begin{array}{l}\text { Water } \\
\text { extraction } \\
\text { followed } \\
\text { by } \\
\text { separation } \\
\text { w/organic } \\
\text { solvents }\end{array}$ & $\begin{array}{l}\text { UPLC- } \\
\text { IMS-MS }\end{array}$ & $\begin{array}{l} \\
7 \\
0 \\
\% \\
\mathrm{M} \\
\text { et } \\
\mathrm{h} \\
\mathrm{a} \\
\mathrm{n} \\
\mathrm{ol} \\
: \\
\mathrm{W}\end{array}$ & $\begin{array}{l}\text { Black tea } \\
\text { thearubigin } \\
\mathrm{S}\end{array}$ & $\begin{array}{l}\text { Resolves } \\
\text { complex } \\
\text { thearubigi } \\
\text { ns } \\
\text { (theasinen } \\
\text { sins) and } \\
\text { flavanol } \\
\text { dimers }\end{array}$ & $\begin{array}{l}\text { Expensive } \\
\text { equipment } \\
\text { and } \\
\text { advanced } \\
\text { calculation } \\
\text { s are } \\
\text { required }\end{array}$ & 7 \\
\hline
\end{tabular}


Nutrition Today

Volume 53, Issue 6, 2018, pages 268-278

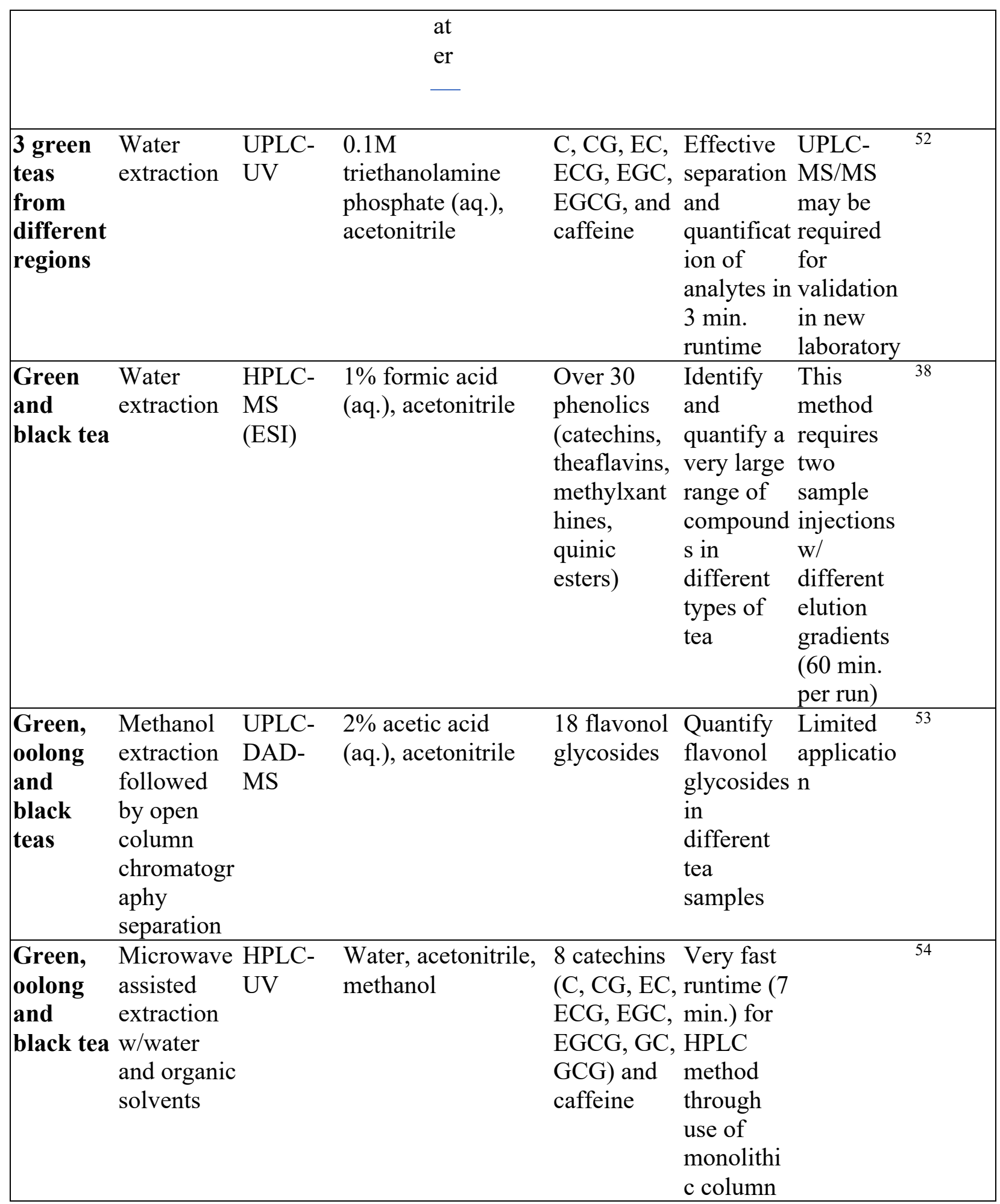

abbreviations: $\mathbf{C}=$ catechin, $\mathbf{C G}=$ catechin gallate, $\mathbf{E C}=$ epicatechin, $\mathbf{E C G}=$ epicatechin gallate, EGC=epigallocatechin, EGCG=epigallocatechin gallate, $\mathbf{G C}=$ gallocatechin, GCG $=$ gallocatechin gallate 
Volume 53, Issue 6, 2018, pages 268-278

Table 3A. Levels of main bioactives reported in instant tea.

\begin{tabular}{|llllll|}
\hline $\begin{array}{l}\text { Tea } \\
\text { type }\end{array}$ & Product & $\begin{array}{l}\text { Catechins } \\
\text { (mg per g) }\end{array}$ & $\begin{array}{l}\text { Theaflavins } \\
\text { (mg per g) }\end{array}$ & $\begin{array}{l}\text { Thearubigins } \\
\text { (mg per g) }\end{array}$ & Reference \\
\hline Green & Powdered & 331.9 & & 21 \\
\cline { 2 - 5 } & $\begin{array}{l}\text { Powdered, } \\
\text { decaffeina } \\
\text { ted }\end{array}$ & & & 55 \\
& $\begin{array}{l}\text { Powdered, } \\
\text { high } \\
\text { caffeine }\end{array}$ & & & 55 \\
\hline Black & Powdered & 94.7 & 3.7 & 298 & 56 \\
\hline
\end{tabular}


Table 3B. Levels of main bioactives in ready-to-drink tea.

\begin{tabular}{|llll|}
\hline Tea type & Product & $\begin{array}{l}\text { Catechins } \\
(\mathbf{m g} \text { per } \mathbf{1 0 0} \mathbf{~ m L})\end{array}$ & Reference \\
\hline Green & Canned & $0.3-35$ & 25 \\
\hline $\begin{array}{l}\text { Oolong } \\
\text { Fermented* }\end{array}$ & Bottled & 32.3 & 25 \\
\cline { 2 - 4 } & Bottled & $8.8-20.7$ & 57 \\
\cline { 2 - 4 } & Canned & $8.8-21.2$ & 57 \\
\cline { 2 - 4 } & $\begin{array}{l}\text { Bottle } \\
\text { (glass) }\end{array}$ & $6.1-26.1$ & 57 \\
\hline $\begin{array}{l}\text { Black } \\
\text { Iced tea }\end{array}$ & Bottled & 6.7 & 58 \\
\cline { 2 - 4 } & Bottled & $0.3-1.8$ & 25 \\
\hline
\end{tabular}

*Tea variety was not specified in the publication.

Unless specified, bottles were PET 


\section{References}

1. Crozier A, Jaganath IB, Clifford MN. Dietary phenolics: chemistry, bioavailability and effects on health. Natural Product Reports. 2009;26(8):1001-1043.

2. Clifford MN, Crozier A. Phytochemicals in teas and tisanes and their bioavailability. In: Crozier A, Ashihara H, Tomas F, eds. Teas, cocoa and coffee: plant secondary metabolites and health. Vol 1. Hoboken, NJ: John Wiley \& Sons; 2011:45-98.

3. Vuong QV. Epidemiological evidence linking tea consumption to human health: a review. Critical reviews in food science and nutrition. 2014;54(4):523-536.

4. Hartley L, Flowers N, Holmes J, et al. Green and Black Tea for the Primary Prevention of Cardiovascular Disease (CVD): A Cochrane Systematic Review. J Epidemiol Community Health. 2013;67(Suppl 1):A52-A53.

5. Peterson J, Dwyer J, Jacques P, Rand W, Prior R, Chui K. Tea variety and brewing techniques influence flavonoid content of black tea. Journal of Food Composition and Analysis. 2004;17(3-4):397-405.

6. Peterson J, Dwyer J, Bhagwat S, et al. Major flavonoids in dry tea. Journal of Food Composition and Analysis. 2005;18(6):487-501.

7. Yassin GH, Grun C, Koek JH, Assaf KI, Kuhnert N. Investigation of isomeric flavanol structures in black tea thearubigins using ultraperformance liquid chromatography coupled to hybrid quadrupole/ion mobility/time of flight mass spectrometry. Journal of Mass Spectrometry. 2014;49(11):1086-1095.

8. Chen C-N, Liang C-M, Lai J-R, Tsai Y-J, Tsay J-S, Lin J-K. Capillary electrophoretic determination of theanine, caffeine, and catechins in fresh tea leaves and oolong tea and their 
effects on rat neurosphere adhesion and migration. Journal of agricultural and food chemistry. 2003;51(25):7495-7503.

9. Lee L-S, Kim S-H, Kim Y-B, Kim Y-C. Quantitative analysis of major constituents in green tea with different plucking periods and their antioxidant activity. Molecules. 2014;19(7):9173-9186.

10. Sang S, Lambert JD, Ho C-T, Yang CS. The chemistry and biotransformation of tea constituents. Pharmacol. Res. 2011;64(2):87-99.

11. Chang K. World tea production and trade: Current and future development. A publication by the Food and Agricultural Organization of the United Nations, Rome. Available online at http://www.fao.org/3/a-i4480e.pdf (date accessed 29 May 2016). 2015.

12. Hilal Y, Engelhardt U. Characterisation of white tea-Comparison to green and black tea. Journal für Verbraucherschutz und Lebensmittelsicherheit. 2007;2(4):414-421.

13. Lv H-p, Zhang Y-j, Lin Z, Liang Y-r. Processing and chemical constituents of Pu-erh tea: a review. Food research international. 2013;53(2):608-618.

14. Tan J, Engelhardt UH, Lin Z, Kaiser N, Maiwald B. Flavonoids, phenolic acids, alkaloids and theanine in different types of authentic Chinese white tea samples. Journal of Food Composition and Analysis. 2017;57:8-15.

15. Rusak G, Komes D, Likić S, Horžić D, Kovač M. Phenolic content and antioxidative capacity of green and white tea extracts depending on extraction conditions and the solvent used. Food Chemistry. 2008;110(4):852-858.

16. Lv SD, Wu YS, Li CW, Xu YQ, Liu L, Meng QX. Comparative Analysis of Pu-erh and Fuzhuan Teas by Fully Automatic Headspace Solid-Phase Microextraction Coupled with Gas 
Volume 53, Issue 6, 2018, pages 268-278

Chromatography-Mass Spectrometry and Chemometric Methods. Journal of Agricultural and Food Chemistry. Feb 2014;62(8):1810-1818.

17. Ahmed S, Unachukwu U, Stepp JR, Peters CM, Long C, Kennelly E. Pu-erh tea tasting in Yunnan, China: Correlation of drinkers' perceptions to phytochemistry. Journal of Ethnopharmacology. 2010;132:176-185.

18. Kuhnert N, Drynan JW, Obuchowicz J, Clifford MN, Witt M. Mass spectrometric characterization of black tea thearubigins leading to an oxidative cascade hypothesis for thearubigin formation. Rapid Communications in Mass Spectrometry. 2010;24(23):3387-3404.

19. Fraser K, Lane GA, Otter DE, et al. Non-targeted analysis by LC-MS of major metabolite changes during the oolong tea manufacturing in New Zealand. Food Chem. 2014;151:394-403.

20. Saltmarsh M. Instant tea. In: Wilson KC, Clifford MN, eds. Tea. Dordrecht, Netherlands: Springer; 1992:535-554.

21. Ortiz J, Ferruzzi M, Taylor L, Mauer L. Interaction of environmental moisture with powdered green tea formulations: effect on catechin chemical stability. Journal of agricultural and food chemistry. 2008;56(11):4068-4077.

22. ITO EN. Integrated Report. https://http://www.itoen.co.jp/eng/pdf/2016/ar/all.pdf. Published October 2016. Accessed February 2, 2018.

23. Zenith Global. Ready-to-drink tea innovations. 2017; https://http://www.zenithglobal.com/reports data/398/Ready-to-drink. Published March 2017. Accessed February 5, 2018.

24. Kumazawa K. Flavor chemistry of tea and coffee drinks. Food science and technology research. 2006;12(2):71-84. 
Volume 53, Issue 6, 2018, pages 268-278

25. Chen Z-Y, Zhu QY, Tsang D, Huang Y. Degradation of green tea catechins in tea drinks. Journal of agricultural and food chemistry. 2001;49(1):477-482.

26. Komatsu Y, Suematsu S, Hisanobu Y, Saigo H, Matsuda R, Hara K. Effects of pH and temperature on reaction kinetics of catechins in green tea infusion. Bioscience, biotechnology, and biochemistry. 1993;57(6):907-910.

27. Grauwet T, Vervoort L, Colle I, Van Loey A, Hendrickx M. From fingerprinting to kinetics in evaluating food quality changes. Trends in biotechnology. 2014;32(3):125-131.

28. Balentine DA, Dwyer JT, Erdman JW, et al. Recommendations on reporting requirements for flavonoids in research. The American Journal of Clinical Nutrition. June 1, 2015 2015;101(6):1113-1125.

29. Lamuela-Raventós RM, Vallverdú-Queralt A, Jáuregui O, Martínez-Huélamo M, QuiferRada P. Improved characterization of polyphenols using liquid chromatography. Polyphenols in Plants: Elsevier; 2014:261-292.

30. Diniz PH, Barbosa MF, de Melo Milanez KD, Pistonesi MF, de Araujo MC. Using UVVis spectroscopy for simultaneous geographical and varietal classification of tea infusions simulating a home-made tea cup. Food Chem. Feb 1 2016;192:374-379.

31. Bhagwat S, Haytowitz DB, Holden JM. USDA Database for Flavonoid Content of Selected Foods. Release 3.1. Beltsville, MD2014.

32. Hicks MB, Hsieh YP, Bell LN. Tea preparation and its influence on methylxanthine concentration. Food Research International. 1996;29(3-4):325-330.

33. Chin JM, Merves ML, Goldberger BA, Sampson-Cone A, Cone EJ. Caffeine content of brewed teas. Journal of Analytical Toxicology. 2008;32(8):702-704. 
Volume 53, Issue 6, 2018, pages 268-278

34. Keenan EK, Finnie MD, Jones PS, Rogers PJ, Priestley CM. How much theanine in a cup of tea? Effects of tea type and method of preparation. Food chemistry. 2011;125(2):588-594.

35. Neilson AP, Green RJ, Wood KV, Ferruzzi MG. High-throughput analysis of catechins and theaflavins by high performance liquid chromatography with diode array detection. Journal of chromatography A. 2006;1132(1):132-140.

36. Henning SM, Aronson W, Niu Y, et al. Tea polyphenols and theaflavins are present in prostate tissue of humans and mice after green and black tea consumption. The Journal of nutrition. 2006;136(7):1839-1843.

37. Henning SM, Wang P, Said JW, et al. Randomized clinical trial of brewed green and black tea in men with prostate cancer prior to prostatectomy: Green and Black Tea in Prostate Cancer. The Prostate. 2015;75(5):550-559.

38. Del Rio D, Stewart AJ, Mullen W, et al. HPLC-MSn analysis of phenolic compounds and purine alkaloids in green and black tea. Journal of agricultural and food chemistry. 2004;52(10):2807.

39. Damiani E, Bacchetti T, Padella L, Tiano L, Carloni P. Antioxidant activity of different white teas: Comparison of hot and cold tea infusions. Journal of Food Composition and Analysis. 2014;33(1):59-66.

40. Khokhar S, Magnusdottir S. Total phenol, catechin, and caffeine contents of teas commonly consumed in the United Kingdom. Journal of Agricultural and Food Chemistry. 2002;50(3):565-570.

41. Peng L, Song X, Shi X, Li J, Ye C. An improved HPLC method for simultaneous determination of phenolic compounds, purine alkaloids and theanine in Camellia species. Journal of Food Composition and Analysis. 2008;21(7):559-563. 
Volume 53, Issue 6, 2018, pages 268-278

42. Zuo Y, Chen H, Deng Y. Simultaneous determination of catechins, caffeine and gallic acids in green, Oolong, black and pu-erh teas using HPLC with a photodiode array detector. Talanta. 2002;57(2):307-316.

43. Henning SM, Wang P, Heber D. Chemopreventive effects of tea in prostate cancer: Green tea versus black tea. Molecular Nutrition \& Food Research. 2011;55(6):905-920.

44. Tan F, Tan C, Zhao A, Li M. Simultaneous determination of free amino acid content in tea infusions by using high-performance liquid chromatography with fluorescence detection coupled with alternating penalty trilinear decomposition algorithm. Journal of agricultural and food chemistry. 2011;59(20):10839-10847.

45. Zhang L, Li N, Ma Z-Z, Tu P-F. Comparison of the chemical constituents of aged Pu-erh tea, ripened Pu-erh tea, and other teas using HPLC-DAD-ESI-MS n. Journal of agricultural and food chemistry. 2011;59(16):8754-8760.

46. Bhuyan LP, Sabhapondit S, Baruah BD, Bordoloi C, Gogoi R, Bhattacharyya P. Polyphenolic compounds and antioxidant activity of CTC black tea of North-East India. Food chemistry. 2013;141(4):3744-3751.

47. Liang Y, Lu J, Zhang L, Wu S, Wu Y. Estimation of black tea quality by analysis of chemical composition and colour difference of tea infusions. Food Chemistry. 2// $2003 ; 80(2): 283-290$.

48. Lakenbrink C, Lapczynski S, Maiwald B, Engelhardt UH. Flavonoids and other polyphenols in consumer brews of tea and other caffeinated beverages. Journal of agricultural and food chemistry. 2000;48(7):2848-2852. 
Volume 53, Issue 6, 2018, pages 268-278

49. Wang Q, Peng C, Gong J. Effects of enzymatic action on the formation of theabrownin during solid state fermentation of Pu-erh tea. Journal of the Science of Food and Agriculture. 2011;91(13):2412-2418.

50. Wang Q, Gong J, Chisti Y, Sirisansaneeyakul S. Bioconversion of tea polyphenols to bioactive theabrownins by Aspergillus fumigatus. Biotechnology Letters. 2014;36(12):25152522.

51. Svoboda P, Vlčková H, Nováková L. Development and validation of UHPLC-MS/MS method for determination of eight naturally occurring catechin derivatives in various tea samples and the role of matrix effects. Journal of pharmaceutical and biomedical analysis. 2015;114:6270.

52. Naldi M, Fiori J, Gotti R, et al. UHPLC determination of catechins for the quality control of green tea. Journal of pharmaceutical and biomedical analysis. 2014;88:307-314.

53. Jiang H, Engelhardt UH, Thräne C, Maiwald B, Stark J. Determination of flavonol glycosides in green tea, oolong tea and black tea by UHPLC compared to HPLC. Food Chem. $2015 ; 183: 30-35$.

54. Rahim A, Nofrizal S, Saad B. Rapid tea catechins and caffeine determination by HPLC using microwave-assisted extraction and silica monolithic column. Food Chem. 2014;147:262268.

55. Vuong QV, Golding JB, Nguyen MH, Roach PD. Preparation of decaffeinated and high caffeine powders from green tea. Powder technology. 2013;233:169-175.

56. Perera GAAR, Amarakoon AMT, Illeperuma DCK, Muthukumarana PKP. Effects of raw material on the chemical composition, organoleptic properties, antioxidant activity, physical 
properties and the yield of instant black tea. LWT-Food Science and Technology. 2015;63(1):745-750.

57. Cordero C, Canale F, Rio DD, Bicchi C. Identification, quantitation, and method validation for flavan-3-ols in fermented ready-to-drink teas from the Italian market using HPLC-UV/DAD and LC-MS/MS. Journal of separation science. 2009;32(21):3643-3651.

58. Del Rio D, Calani L, Scazzina F, Jechiu L, Cordero C, Brighenti F. Bioavailability of catechins from ready-to-drink tea. Nutrition. 2010;26(5):528-533. 